\title{
Pioneering patterns of ballast treatment in the emerging era of marine vector management
}

Ian C. Davidson*, Mark S. Minton, Katherine J. Carney, A. Whitman Miller, Gregory M. Ruiz

Keywords: vector management, ballast water, treatment technology, invasive species 


\begin{abstract}
Human-mediated transfer and invasions of organisms have permanently altered distribution patterns on a global scale. In response to growing numbers and impacts of invasions, global-scale vector management is advancing to curtail unintentional and unwanted species re-distributions. In marine systems, ocean-going ships have been the major dispersal mechanism across biogeographic barriers, and maritime vector management has become a priority global initiative, including national regulations and recent ratification of an international convention to manage ballast water. This paper provides the first analysis of the pioneering patterns of ballast water treatment systems (BWTS) on board commercial ships, using vessel arrivals to the United States as a model system. Over an opening 28-month period, $>200$ unique vessels arriving to the U.S. reported BWTS operations, using 58 different systems to treat 4.42 million $\mathrm{m}^{3}$ of discharged ballast water. Although this volume represents $<2 \%$ of all ballast water discharged in the U.S. per month during this period, there was substantial growth in treated ballast discharge throughout this time. Through 2015, 'Filtration + UV' systems were the most common BW'TS type installed across all ship types. Currently, BWTSs occur on higher numbers of tankers and bulkers, but a higher proportion of passenger vessels, than other ship types. If BWTSs meet the required discharge standards as intended, this will cause a steep reduction in total discharge of organisms $\geq 50 \mu \mathrm{m}$ compared to current practices. While several hurdles in fleet-wide BWTS adoption remain, including the timeline for BWTS installation across the global fleet, we are at a significant milestone in the history and evolution of global shipping, which is undergoing wholesale transition to a new and more effective global-scale ballast vector management strategy.
\end{abstract}




\section{Pioneering patterns of ballast treatment in the emerging era of marine vector management}

\section{INTRODUCTION}

The Anthropocene has brought about permanent human-induced changes to global biogeography via intentional and unintentional transfers of organisms among the world's bioregions [1,2]. As a result, the field of vector ecology and management has emerged to understand and curtail the transfer and introduction of organisms beyond their native ranges [3]. In marine systems, ships have played the most significant role in the global redistribution of species, from the earliest seafaring times to the present day. Two sub-vectors of ships, biofouling of submerged surfaces and ballast (first as solid ballast and then as ballast water), have been a leading cause of coastal marine invasions for centuries, affecting major shifts in community composition in bays and estuaries around the world [4]. The vector management challenge for global shipping is formidable, but important progress has been made to reduce worldwide species translocations that have been largely uninterrupted for a centuries-old vector.

The control and management of ships' ballast water (BW), which is one of the largest vector management initiatives in the world, gained significant momentum in the late 1980s and early 1990s in Canada and the United States (U.S.) after major ballast-mediated spread of epidemic cholera and outbreaks of zebra mussels [5, 6]. BW management is currently entering a new phase, whereby ships will soon be required to meet new standards for BW discharge (indeed, some new builds and recently dry docked vessels are already subject to these standards). In response, ships have begun to transition from open-ocean exchange of BW to onboard treatment technologies to reduce organism concentrations in ballast discharges. This is driven by national regulations and further reinforced by the recent ratification of the International Maritime Organization's (IMO) Ballast Water Management Convention, which will come into force in September 2017 [7]. Provisions for ballast management in the convention are similar to U.S. regulations but apply to the global fleet [8], possibly accelerating the transition from ballast exchange to concentration-based limits on organism discharge. Onboard treatment technology, if operating properly, offers a global solution to reduce delivery of BW-borne biota with implementation focused on the vectors themselves rather than recipient ports or regions. 
This analysis characterized the emergence of ballast water treatment systems (BWTSs) onboard commercial ships that arrived to the U.S., beginning with the first case in September 2013 and tracking through December 2015. This is the first fleet characterization of this form of ballast management and describes the pioneering patterns of BWTS adoption for any population of the world's ships. Variation in BWTS usage over time, among ship types, and in the context of total BW delivery to the U.S was examined. Results show that the use of treatment systems is now underway across a range of ship types that operate under a variety of ballast discharge challenges.

\section{MATERIAL AND METHODS}

In the U.S., BWTSs are subject to an approval process that is overseen by the U.S. Coast Guard (Code of Federal Regulation 33 CFR 151 subpart D). Currently, there are two paths toward BWTS approval for use in U.S. waters: a specific USCG type-approval that requires vendors to have their BWTS subjected to testing at USCG-approved testing facilities, or a provisional (temporary) approval of 'alternative management systems' (AMS) for BWTS that have yet to meet the requirements of USCG type-approval but have completed testing under the auspices of the IMO and other jurisdictions. Very recently (in December 2016), three BWTS have been type-approved by the USCG, but all of the systems reported in these analyses of BWTS usage were operating under provisional approval and reported BWTS activity on BW management reporting forms.

Data were collated from the U.S. National Ballast Information Clearinghouse (NBIC) from September 2013, the first month in which a ship reported a BWTS under USCG AMS rules, through December 2015. The USCG regulates BW discharge in the U.S., and ships are required to report their arrival and ballast activity to NBIC for nearly all arrivals to ports and places in U.S. waters. Each vessel reports information on voyage particulars, including the type and name of BWTS on board, the total ballast water capacity and ballast on board, the source and discharge locations of any ballast water to be discharged by the ship, and whether it has undergone BW management of any kind.

For this 28-month time period, the numbers of ships with installed BWTSs on board by ship type and BW'TS type were quantified. Temporal patterns of BWTS occurrence on the commercial fleet arriving to U.S. ports as a proportion of all unique vessel arrivals were examined. The amount of BW treated using BWTSs was investigated in absolute terms, relative to all BW managed by the sub- 
population of ships with BWTS on board, and relative to the total BW arriving for discharge at U.S. ports.

\section{RESULTS}

During the first 28 months of BWTS reporting in the United States, 58 different systems were accepted by the USCG for use in U.S. waters. These systems belong to seven categories based on their operational profile: advanced oxidation, deoxygenation, electrolytic, filtration, filtration + UV, heat + deoxygenation, and ozone. Filtration combined with UV radiation ('filtration + UV') was the most numerous category with 25 different systems accepted by USCG, while three BWTS categories were represented by just one system each (Table 1). These systems were reported to be installed on 202 unique vessels that have arrived to U.S. ports, representing a monthly and steady cumulative increase in more than two years since their adoption (Fig. 1).

\section{Figure 1 here}

\section{Table 1 here}

The most widely installed BWTSs aboard ships aligned with the numbers of systems per category that have been approved by USCG. 'Filtration + UV', 'electrolytic', and 'advanced oxidation' systems were installed on 71, 70, and 53 ships, respectively. BWTSs were installed on more bulkers and tankers than other ship types, but on a higher proportion of passenger vessels than other ship types (Fig. 2). The three most frequently installed types of BWTS were reported across a range of ship types rather than any particular vessel type. For repeated arrivals of vessels with BWTSs over the sample period, 'filtration + UV' systems have been reported far more frequently than any other system type - there were 1854 distinct arrivals with 'filtration + UV' systems on board vessels, which was $187 \%$ higher than all other systems combined.

\section{Figure 2 here}

On average, $67 \%( \pm 12 \%$ S.D.) of vessels with BWTSs onboard reported discharging BW on a monthly basis, but $17 \%( \pm 7 \%)$ fewer discharged BWTS-treated water per month (i.e. $50 \%$ of vessels with BWTS discharged BWTS-treated water per month; Fig. 3a). The cumulative BW treated and discharged by BW'TSs up to December 2015 was 4.4 million $\mathrm{m}^{3}$ from 2848 arrivals. The overall growth of BWTS-treated ballast water discharge was based on increased frequency of de-ballasting 
events rather than an increase in volume of treated water per event. October 2013, the second month of BWTS reporting, had the highest average discharge of treated BW per arrival, and the maximum discharge of treated water (for a single discharge event) in that month was $24,719 \mathrm{~m}^{3}$. Total treated ballast discharge increased $780 \%$ from the first to last month of the sample period, but the average volume per discharge event per month was relatively stable at $7 \times 10^{3} \mathrm{~m}^{3}\left( \pm 2.6 \times 10^{3} \mathrm{~m}^{3}\right.$; Fig. 3b). Despite the growing number of vessels having BWTSs on board, less than $2 \%$ of monthly BW discharge volume in the U.S. throughout the time period was actually treated (Fig. 3c). If functioning according IMO and U.S. discharge standards, the total discharge of BWTS-treated water should have released fewer than 44.22 million organisms of $\geq 50 \mu \mathrm{m}$ into U.S. coastal waters (fewer than 10 organisms $\geq 50 \mu \mathrm{m}$ per cubic meter $\times$ discharged water).

\section{Figure 3 here}

\section{Discussion}

These data show that the initial emergence of BWTS onboard ships is occurring with a range of different technologies across nearly all ship-types engaged in maritime trade, despite the small proportion of ships (representing $<3 \%$ of monthly arrivals) and ballast volumes involved thus far. This represents a leading edge of a vector management initiative that should expand dramatically in the coming years. Ships' BW is a major conveyance of organisms across and among oceans, conservatively estimated at several thousand species and millions of individual organisms in transit per day [9], not including phytoplankton and microbial organisms. As a result, the 130-year history of BW transfer is a history of biodiversity exchange on a global scale [10], creating major shifts in species' range sizes and distributions with largely unknown longer-term consequences for community assembly and species diversification. In addition, a subset of species cause remarkable shifts in ecosystems or dramatic damage to economic interests, which is a strong motivation for control and management $[9,11]$. Open-ocean exchange of BW has been shown to reduce the risk of transfer, discharge, and invasion by organisms [12,13] and the move to numerical limits of organism concentrations discharged by ships is intended to reduce risk even further. As such, BW treatment represents a new wave of international vector management that may further reduce the likelihood of homogenizing the world's coastal biota and some of the impacts that can occur as a result. 
The relatively high number (58) and diversity of BWTSs appearing on ships in the first 28 months of their reported use in the U.S. reflects the commercial incentive to BW'TS vendors competing for market share. From a conservation perspective, this is encouraging because a range of options are being developed that may cater to the variety of ballast operations that exist, while regulatory compliance will be heavily dependent on this market in coming years [14]. A range of BWTS technologies have been installed across and within ship types and variation in system adoption across ship type should be expected based on well-known variation in ballast volumes, operations, and management needs among them $[15,16]$. Indeed, many individual BWTSs are designed in size/ capacity increments to cater to different scales of ballast operations (according to flow rates that typically correspond to the size of vessels). Furthermore, system requirements for ballast holding times may impose limitations on certain vessels or voyage routes (e.g., coastwise versus trans-ocean) and system suitability or duration of treatment may differentiate adoption of technology across the fleet. For example, some BWTSs specify a 12-hour holding time to complete treatment processes [17], a probable limitation for certain voyage routes that require BW management. Type approval testing is intended to determine whether systems can perform to discharge standards in a range of circumstances (e.g., in different salinities), but it is a benefit that numerous approaches can be used to attain the standard, since a diversity of technologies will better match the range of ships (and voyage circumstances) that are required to manage their ballast water. Trade-offs in how systems handle different volumes, holding times, and other factors should materialize within the fleet as treatment systems become more prevalent and lead to optimization of technologies to specific ship types and behaviors.

Several constraints on the efficacy of onboard ballast treatment have been reported that highlight the dynamic nature of this vector's management going forward. First, although discharge standards will likely provide a significant improvement to invasion risk reduction compared to the status quo of un-exchanged and exchanged BW, large inoculation events will persist [18]. Second, the ability of BWTS to achieve discharge standards remains an ongoing concern, especially as it relates to smaller organisms and microbes $(\geq 10-50 \mu \mathrm{m}$ and $<10 \mu \mathrm{m})$ and population re-growth in ballast tanks [19, 20]. This has contributed to the low numbers of vessels with BWTS during the initial months of reporting in the U.S.; the stark reality is that if achieving the standard was straightforward, then more systems would be available and more ships would undoubtedly have systems installed. Third, typeapproval testing represents a bottleneck in BWTS market emergence, testing BW discharge to the standard requires large volumes of water for statistical rigor [21], and specific test protocols vary 
somewhat by region [19] and produce some uncertainty about results. Fourth, there are concerns regarding pollution by-products from some chemical treatments and their persistence and impact on coastal systems [22, 23].

Furthermore, while water treatment on land employs mature technologies, treatment of large volumes in relatively small spaces and operational tempos of ships is a significant engineering challenge [15]. Initial volumes of water treated by BWTSs for U.S. arrivals represented a minor proportion of overall BW that was discharged. Greater variation in the size of treated discharge events over time is expected compared to the first 28 months reflected in U.S. data. It is likely that the initial months after installation involve a training period for the use of ship board BWTSs under single tank or small volume scenarios, although some large individual discharge events were noted early in the sample period. Finally, BWTS installation timelines are uncertain and the cost of retrofitting BWTS onboard vessels is substantially higher than installing BWTS in new builds [14]. Each constraint applies pressure to timelines for mandatory compliance with environmental standards that are either in existing national regulation or about to enter into force internationally. While these many concerns are important to address, they should not be mistaken as broader criticism of ballast management as a whole. It is important not to lose sight of the ambitious scale of this endeavor and overall progress that is being made in maritime vector management more broadly.

This emerging era of maritime vector management has focused increasingly on vessel biofouling, aquaculture shipments, live bait, ornamental trade, and indeed BW among other vectors [24], representing significant advances, broader awareness, and international-scale agreement to reduce invasions [e.g. 7]). The example of ship biofouling management as an explicit biosecurity measure is also informative; existing hull husbandry strategies that contribute to biosecurity goals are largely a by-product of industry-driven management for hull performance and vessel efficiency, but gaps between biofouling management for ship performance versus biosecurity have been identified and are the focus on new initiatives, despite some contention [25]. Each example across a range of challenging marine species vectors demonstrates how vector ecology and management has emerged and the adoption and scale of those efforts is expanding. In concert with other green shipping initiatives like pollution and emission control, there is important progress and great scope for further improvement in reducing the environmental footprint of maritime shipping [26]. 
Under a range of concerns and criticisms regarding the complexity and duration of ballast water policy development, IMO and other jurisdictional procedures, BWTS development, type-approval testing, and installation and compliance schedules, it is easy to forget that BW management is just 20-25 years old compared to a maritime history of species translocations that is centuries old and a $\mathrm{BW}$ vector that is 130 years old. It is unlikely that the role of maritime shipping in global commerce and connectivity will diminish substantially, so it is important that gains in reducing long-term environmental impacts not be starkly overshadowed by shorter term complexities in implementing prudent vector management. Despite formidable challenges in generating international scale environmental management requiring technological innovation, the emerging patterns of BWTS adoption across the commercial shipping fleet provide a basis for optimism toward the goal of reducing artificial, inadvertent, and unwanted biotic interchange on a global scale.

\section{Acknowledgements}

This work was funded by the U.S. Coast Guard and the Smithsonian Institution. We thank Dr. Richard Everett of the U.S. Coast Guard for insights and discussions.

\section{References}

1. P.E. Hulme, Trade, transport and trouble: managing invasive species pathways in an era of globalization. J. App. Ecol. 46 (2009) 10-18.

2. S.L. Lewis, M.A. Maslin, Defining the Anthropocene. Nature 519 (2015) 171-180.

3. G.M. Ruiz, J.T. Carlton, Invasive species: vectors and management strategies. Island Press, Washington DC. (2003) 484pp.

4. J.T. Carlton, Man's role in changing the face of the ocean: biological invasions and implications for conservation of near-shore environments. Cons. Biol. 3 (1989) 265-273.

5. L. Roberts, Zebra mussel invasion threatens U.S. waters. Science 249 (1990) 1370-1372.

6. S.A. McCarthy, F.M. Khambati, International dissemination of epidemic Vibrio cholera by cargo ship ballast and other nonpotable waters. Appl. Environ. Microbiol. 60 (1994) 2597-2601.

7. International Maritime Organization, Global treaty to halt invasive aquatic species to enter into force in 2017. (2016) Briefing 08/09/2016. http://www.imo.org/en/MediaCentre/ PressBriefings/Pages/22-BWM-.aspx

8. International Maritime Organization, International convention for the control and management of ships ballast water and sediments. BWM/CONF/36 (2004) London, UK. 16 February 2004. 
9. J.T. Carlton, J.B. Geller, Ecological roulette: the global transport of nonindigenous marine organisms. Science 261 (1993) 78-82.

10. J. T. Carlton, Transoceanic and interoceanic dispersal of coastal marine organisms: the biology of ballast water. Oceanogr. Mar. Biol. Ann. Rev. 23 (1985) 313-371.

11. I.C. Davidson, C. Simkanin C, The biology of ballast water 25 years later. Biol. Invasions 14 (2012) 9-13.

12. S.A. Bailey, M.G. Deneau, L. Jean, C.J. Wiley, B. Leung, H. MacIsaac, Evaluating efficacy of an environmental policy to prevent biological invasions. Environ. Sci. Technol. 45 (2011) 2554-2561.

13. V. Molina, L.A. Drake, Efficacy of open-ocean ballast water exchange: a review. Manag. Biol. Invasion. 7 (2106) 1-14.

14. D.M. King, P.T. Hagan, M. Riggio, D.A. Wright, Preview of global ballast water treatment markets. J. Mar. Eng. Technol. 11 (2012) 3-15.

15. National Research Council, Stemming the tide: Controlling introductions of nonindigenous species by ships' ballast water. National Academy Press, Washington DC. (1996) 141pp.

16. E. Verling, G.M. Ruiz, L.D. Smith, B. Galil, A.W. Miller, K.R. Murphy (2005) Supply-side invasion ecology: characterizing propagule pressure in coastal ecosystems. Proc. Roy. Soc. B. 272 (2005) 1249-1257.

17. U.S. Coast Guard, Alternate management system acceptance - revision. US Coast Guard AMS program letter, Jiangsu Nanji Machinery Company, Ltd. January 25, 2016. (2016) Washington DC. 4pp.

18. M.S. Minton, E. Verling, A.W. Miller, G.M. Ruiz, Reducing propagule supply and coastal invasions via ships: effects of emerging strategies. Front. Ecol. Environ. 3 (2005) 304-308.

19. A.N. Cohen, F.C. Dobbs, Failure of the public health testing program for ballast water treatment systems. Mar. Poll. Bull. 91 (2015) 29-34.

20. C Grob, BG Pollet, Regrowth in ships' ballast water tanks: Think again! Mar. Poll. Bull. 109 (2016) 46-48.

21. A.W. Miller, M. Frazier, G.E. Smith, E.S. Perry, G.M. Ruiz, M.N. Tamburri, Enumerating sparse organisms in ships' ballast water: why counting to 10 is not so easy. Environ. Sci. Technol. 45 (2011) 3539-3546.

22. E. Tsolaki, E. Diamadopolous, Technologies for ballast water treatment: a review. J. Chem. Technol. Biotechnol. 85 (2010) 19-32. 
23. B Werschkun et al., Emerging risks from ballast water treatment: The run-up to the international ballast water management convention. Chemosphere 112 (2014) 256-266.

24. S.L. Williams, I.C. Davidson, J.R. Pasari, G.V. Ashton, J.T. Carlton, R.E. Crafton, R.E. Fontana, E.D. Grosholz, A.W. Miller, G.M. Ruiz, C.J. Zabin, Managing multiple vectors for marine invasions in an increasingly connected world. Bioscience 63 (2013) 952-966.

25. I. Davidson, C. Scianni, C. Hewitt, R. Everett, E. Holm, M. Tamburri, G. Ruiz, Mini Review: Assessing the drivers of ship biofouling management - aligning industry and biosecurity goals. Biofouling 32 (2016) 411-428.

26. Z. Wan, M. Zhu, S. Chen, D. Sperling, Three steps to a green shipping industry. Nature 530 (2016) 275-277. 


\section{Figure Captions}

Fig. 1. Cumulative and monthly growth of ships reporting ballast water treatment systems (BWTSs) on board for arrivals to U.S. ports between September 2013 and December 2105.

Fig. 2. (a) The proportion of each vessel type that reported a ballast water treatment systems (BWTS) onboard and (b) the numbers of unique vessels that reported each category of BWTS on board for ships arriving to U.S. ports between September 2013 and December 2105. Reefer and RoRo ship types refer to refrigerated cargo ships and roll-on-roll-off (automobile carrier) vessels, respectively.

Fig. 3. (a) The proportion of vessels with ballast water treatment systems (BWTSs) onboard that reported discharge of BWTS-treated BW (grey), reported discharge of BW that was not treated by BWTSs (black), and reported no BW discharge (white); (b) monthly total volumes of BWTS-treated BW discharge to the U.S. and mean volume per discharge event; and (c) the proportion of all BW discharged represented by BW'TS-treated discharge per month. 
Figure 1.

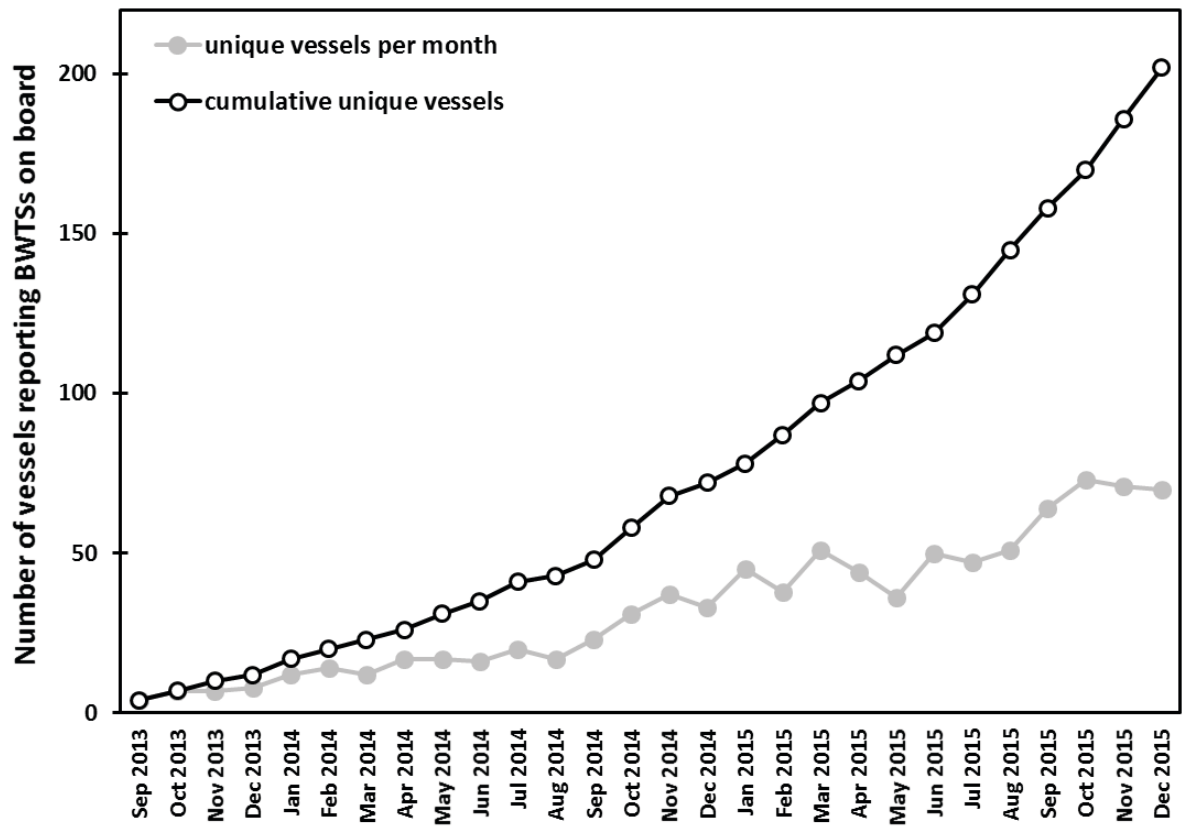


Figure 2
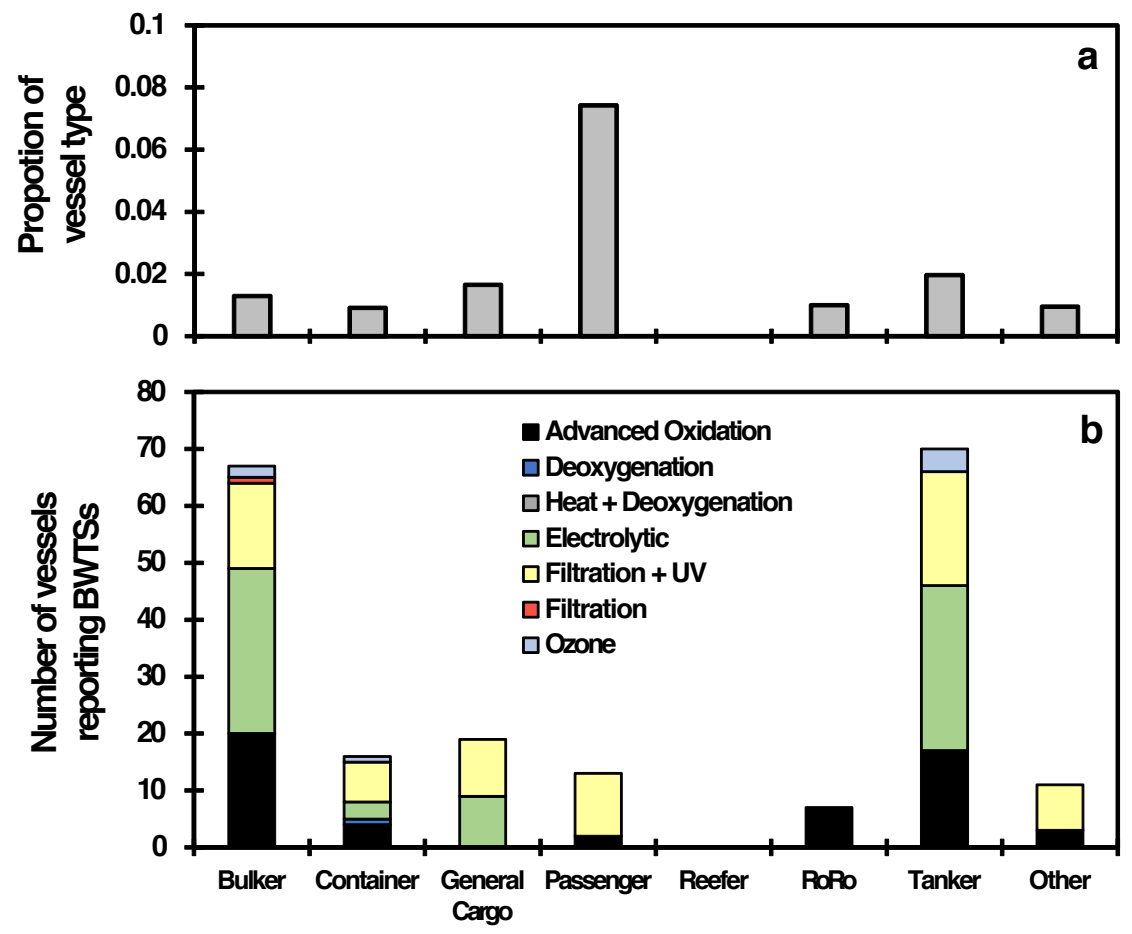

Ship type 
Figure 3
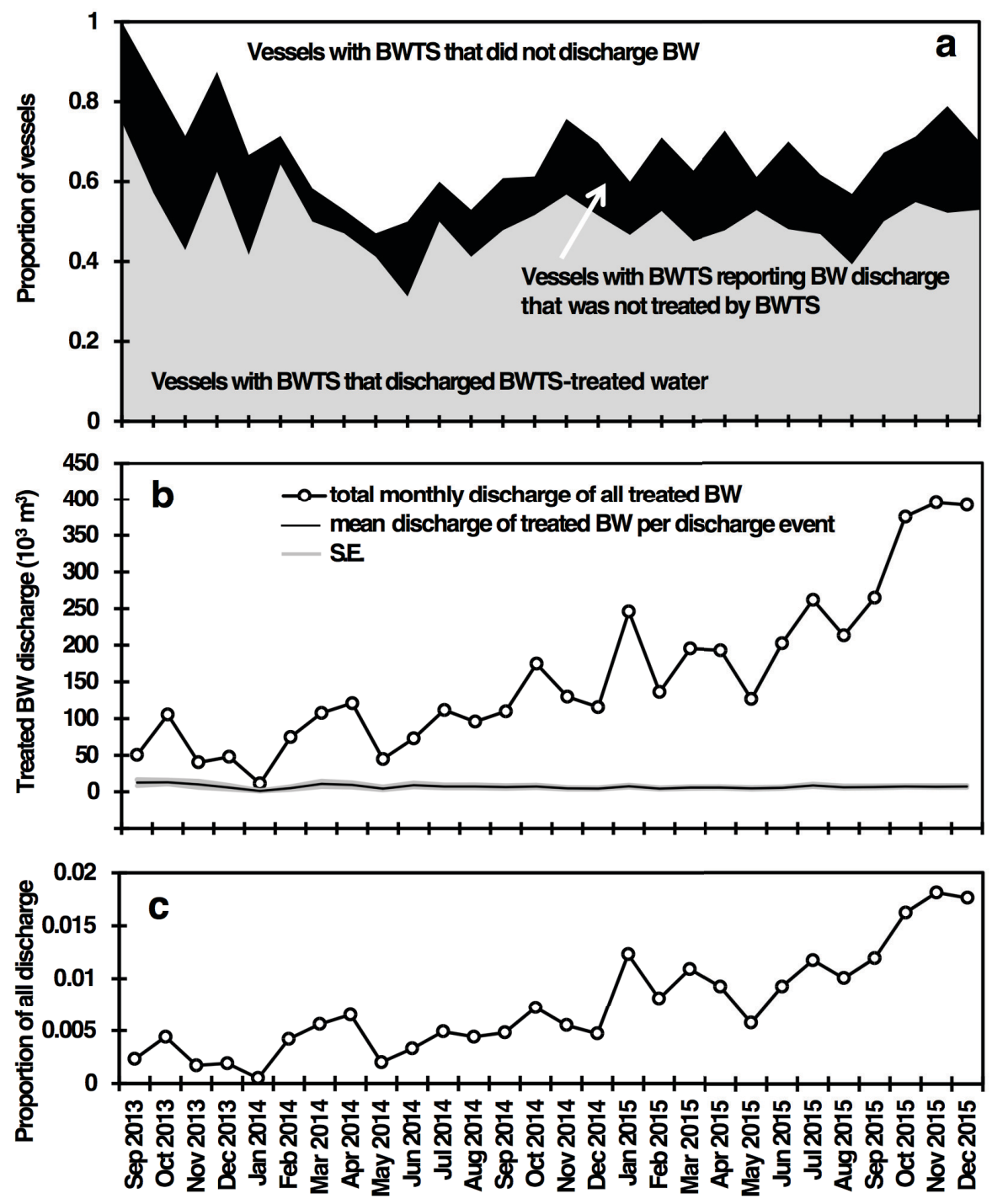
Table

Table 1. Categories and numbers of ballast water treatment systems (BWTSs) that were accepted for use in U.S. waters between September 2013 and December 2015 (or alternative management systems (AMS)). Note: the systems accepted for use by USCG in this time period reflect provisional approval based on IMO-guided testing by other administrations (type-approval elsewhere), not 'U.S. type-approval' by USCG approved testing facilities. BWTS categories are based on USCG criteria and described based on [22].

\begin{tabular}{llc}
\hline System type & Operational background & $\begin{array}{l}\text { Number of } \\
\text { systems accepted } \\
\text { for use by USCG* }\end{array}$ \\
\hline Advanced oxidation & Addition of oxidizing biocides (e.g. chlorine, chlorine dioxide) & 11 \\
\hline Deoxygenation & $\begin{array}{l}\text { Stripping oxygen out by mechanical or chemical means, often by } \\
\text { bubbling nitrogen or other gases into ballast water }\end{array}$ & 3 \\
\hline Electrolytic & $\begin{array}{l}\text { Electrodes are used to generate electrochemical reactions in seawater } \\
\text { to generate biocide (e.g. sodium hypochlorite) }\end{array}$ & 16 \\
\hline Filtration & $\begin{array}{l}\text { Physical separation of organisms from water using screen filters or } \\
\text { cyclonic separation }\end{array}$ & 25 \\
\hline Filtration + UV & $\begin{array}{l}\text { Filtration (above) followed by ultraviolet radiation to cause } \\
\text { photochemical reactions (damage/death) in organisms }\end{array}$ & 1 \\
\hline Heat + deoxygenation & $\begin{array}{l}\text { Mechanical heating of water (above } 40^{\circ} \mathrm{C} \text { ) using waste heat, back-up } \\
\text { boilers, or new heat systems combined with deoxygenation (above) }\end{array}$ & 1 \\
\hline Ozone & $\begin{array}{l}\text { Chemical treatment involving the addition of ozone, an oxidizing } \\
\text { agent }\end{array}$ \\
\hline
\end{tabular}

*between September 2013 and December 2015 